\title{
KEHAOSASÕNADE ARVUKATEGOORIAST
}

\author{
KATRE ÕIM, ASTA ÕIM
}

$\mathrm{P}$

aul Alvre on oma eesti kirja- ja murdekeele morfoloogia käsitluses juhtinud tähelepanu sellistele ainsusevormidele, mis on grammatiliselt korrektsed, kuid justkui ebaloogilised, sest tähendavad mitmust (Alvre 1989:

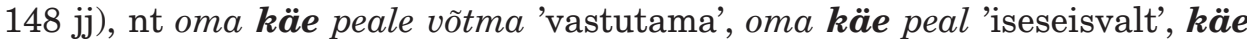
pealt elama 'teenima'. Ainsuse tarvitamine ongi varem olnud ulatuslikum, kuid absoluutarvu mõttes võib see ka praegu igasuguse formatiivita väljendada mitmuslikke mõisteid. Rohkem kui ühte objekti tähistavad eesti keeles arvsõnadega hulgafraasid (viis poissi); paariskehaosade nimetused (oma jalga viima); hammaste, juuste jt (rühma)nimetused (Koer kasvab, hammas kas$v a b k a$ ); marjade, (puu)viljade, lillede, loomade ja kalade nimetused (maasikale, kalale minema); kehaosade ja esemete nimetused, mida igal omajal on üks: kõik raputasid pead (Alvre 1989: 68). Tänapäeva keelekasutuse võrdlus Wiedemanni sõnaraamatuga näitab Alvre hinnangul mitmuse tähenduses ainsuse taandarengut, piirdudes põhiliselt idiomaatilise keelekasutusega. Sama tendents on täheldatav ka soome keeles: jalkaan jalkoihin, hänellä on hätä kiire kädessä käsissä (Alvre 1989: 150-159). Sellest võib järeldada, et kõnealune mõistestusviis ei ole enam produktiivne.

Kadri Muischneki (2006: 95-98) uurimuse kohaselt ei domineeri kumbki kõnealune vorm. Tema järgi on tänapäeval läbipaistvates idiomaatilistes ühendites mitmusevormis käändsõna tüüpiliselt somaatiline (jääb jalgu). Läbipaistmatutes idioomides mitmuses käändsõnu Muischneki materjalis (300 000 sõna) ei esinegi. Mõnes läbipaistvas idiomaatilises ja/või kollokatiivses ühendis saab ühte ja sama käändsõna kasutada nii ainsuses kui ka mitmuses (teeb silma $\sim$ silmi) või ühildada selle subjektiga arvus: tema murrab pead, nemad murravad päid. Kantseliitlikes tugiverbiühendites võib käändsõna olla mitmuses leksikaliseerunud: esitab pretensioone.

Neist suundumustest lähtuvalt on artikli eesmärk teha kindlaks, 1) mille poolest erineb kehaosasõnade ainsuse ja mitmuse esinemissagedus idiomaatilistes ja mitteidiomaatilistes ühendites vanemas ja tänapäeva keeles; 2) mis võib arvukategooria tavapärast loogilist süntaksit järgivat või mittejärgivat allkeeliti erinevat ainsuse ja mitmuse jaotust mõjutada ja mis mitte. Kehaosasõnade arvu mõjutajate uurimiseks arvutame ainsuse- ja mitmusevormide reaalsete sageduste põhjal välja teoreetilised sagedused ning teeme hii-ruuttesti. Tahame teada, kas saame oma valimi ja selles nähtavate seoste põhjal väita, et need seosed on olemas ka üldkogumis (vt Tammaru 2002).

Kuna kõikide mitmuse tähenduses kasutatud ainsusevormide leidmine korpustest eeldaks automaatset semantilist analüüsi, jääb vanade nuumerussuhete süsteemne kirjeldamine tänapäeva eesti keeles tulevikku. 


\section{Andmed ja andmeallikad}

Oleme oma uurimisobjektiks valinud somaatilised nimisõnad: paariskehaosa nimetused käsi ja jalg ning neile mõneti vastanduva, s.o 'paari' tähenduseta suu. Algselt analüüsi kaasatud, samuti paariskehaosi tähistavad sõnad silm ja kõrv jätsime nende suhteliselt avarama grammatilise homonüümia pärast analüüsist välja, vrd näiteks substantiiv kõrv sg allatiivis, adessiivis ja ablatiivis ning kaassõnad kõrvale, kõrval ja kõrvalt.

Meie uurimismaterjali moodustavad lekseemide käsi, jalg, suu vormid, mis leiduvad eesti fraseologismide elektroonilises alussõnastikus (FES), tänapäeva eesti keele metafoorsete sõnaühendite korpuses (MetafK - Eesti Keele Instituudi tekstikorpuse, Tartu Ülikooli eesti kirjakeele korpuse ja eesti keele koondkorpuse materjal) ning eestikeelsete veebilehtede korpuses (etTenTen). Tähtsustame nende, väga erineva sisu ja mahuga korpuste juures kehaosasõnade üksteisega kombineeruvaid tunnuseid, nagu ajaline kuuluvus, register, automaatselt eristatud keeleüksuse, sageduse, tähenduse ja konstruktsiooni tüüp ning morfoanalüüsi tulemuse kvaliteet (vt tabelit 1), millest peame omakorda olulisimaks tähenduse tüüpi (idiomaatiline või mitteidiomaatiline) ja ajalist kuuluvust (varasem või tänapäeva eesti keel). Seoseid kehaosasõnade tunnuste vahel (vt tabelit 8 allpool) selgitame ja testime artikli teises pooles.

Tabel 1 .

\section{Andmeallikad}

\begin{tabular}{|c|c|c|c|}
\hline $\begin{array}{l}\text { uurimisobjekti } \\
\text { tunnused }\end{array}$ & FES & MetafK & etTenTen \\
\hline AJALINE KUULUVUS & XX saj I pool & $1980-2011$ & $\begin{array}{c}\text { XX saj lõpp-XXI saj } \\
\text { algus }\end{array}$ \\
\hline REGISTER & argivestlus murdekeeles & $\begin{array}{l}\text { kirjalik redigeeritud } \\
\text { argisuhtlus }\end{array}$ & kirjalik argisuhtlus \\
\hline $\begin{array}{l}\text { AUTOMAATSELT ERISTATUD } \\
\text { KEELEÜKSUSE TÜÜP }\end{array}$ & lemma & sõne & tekstilause \\
\hline SAGEDUSE TÜÜP & sõnastikusagedus & \multicolumn{2}{|c|}{ tekstisagedus } \\
\hline TÄHENDUSE TÜÜP & \multicolumn{2}{|c|}{ idiomaatiline tähendus } & $\begin{array}{l}\text { otse- või idiomaatiline } \\
\text { tähendus }\end{array}$ \\
\hline KONSTRUKTSIOONI TÜÜP & \multicolumn{2}{|c|}{ fraas või lause } & lause \\
\hline
\end{tabular}

FES hõlmab põhiliselt eelmise sajandi algupoole (murdekeeles) argivestlusi, sisaldades seega vanemaid idiomaatilisi fraase ja lauseid. Viimased on morfoloogiliselt analüüsitud ja homonüümsed vormid käsitsi ühestatud. Artiklis arvestame selliste fraseologismide sõnastikusagedusega, mis sisaldavad lekseemi käsi, jalg või suu, näiteks nagu ei saa sõna suust.

MetafK esindab tänapäeva kirjalikku redigeeritud argisuhtlust. Tegemist on metafoorses tähenduses jm idiomaatiliste fraaside ja lausetega, mis on käsitsi kogutud 1) EKI tekstikorpuse rubriikidest „Ajalehed”, „Ajakirjad jm väljaanded”, „Ilukirjandus” (1990-ndad-2011); 2) eesti kirjakeele korpuse allkorpustest „1980-ndad: Ajakirjandustekstid” ja „1990-ndad: Ajakirjandustekstid, Ilukirjandus”; 3) eesti keele koondkorpuse allkorpusest „Eesti Päevaleht 2006, 2007”. Materjal on morfoloogiliselt analüüsitud, homonüümsete vormide 
hulgast on automaatselt valitud esimene, mis ei pruugi olla õige, nagu näiteks suud: suu pl nominatiivis või sg partitiivis. Artiklis arvestame lekseemi käsi, jalg või suu sisaldavate idiomaatiliste sõnaühendite tekstisagedusega, näiteks sõnagi suust saamata, ei saanud sõna suust, saan sõna suust jne.

Veebilehtede korpus etTenTen sisaldab tekste nii tänapäeva kirjalikust redigeeritud ametlikust suhtlusest kui ka spontaansest argisest internetisuhtlusest. Need on alla laaditud eestikeelsetelt veebilehtedelt ning lausestatud, morfoloogiliselt analüüsitud ja homonüümsed vormid automaatselt ühestatud (etTenTen), vrd käsi sg nominatiivis: Aga haige hõorub käsi ja Nagu segaks neid kogu aeg kellegi kiuslik käsi. Artiklis arvestame etTenTen-i kasutajaliidese väljastatud tekstilausete arvuga, mis sisaldavad kas otseses või idiomaatilises tähenduses lekseemi käsi, jalg või suu: .. kähistas vaevaga sõna suust, mis seal siis laulust rääkida.

\section{Kehaosasõnade mitmuse tähenduses ainsusevormid}

\subsection{Arhailine mõistestus}

Paariskehaosa nimetuste ainsuslikku mitmust, nagu näiteks fraseologismis ei liiguta kätt ega jalga 'oimetu, kontaktitu', võib seletada sellega, et need pole eesti obliikvakäänete mitmusega kohanenud. Viimane on tekkinud suhteliselt hilja, läänemeresoome-lapi ühisperioodil. Abstraktseks muutunud tähenduse tõttu võib tänapäeval jääda selgusetuks, kas mõni ainsusevorm on algselt märkinud üht või mõlemat kehaosa: käe all 'juuresolekul; allutama; õpetama', käest kätte 'ühelt teisele', vrd suust suhu 'levima' (FES). Vastukaaluks sellisele, teistsugust loogikat järgivale ainsusele, võib liitsõna mitmuslik täiendosa Alvre hinnangul mõnikord tunduda kahe kehaosa ülepakutud rõhutamisena: käterätik, käteharjutus. Enne obliikvakäänete mitmuse tekkimist käändusid leksikaalsete ja süntaktiliste vahenditega väljendatud ainsus ja mitmus ühtmoodi. Kui ainsuse nimetavas käsi ja jalg tähendasid käte- ja jalapaari, siis enamaarvulisi kehaosi märgiti mitmuse nimetava tunnusega $-t>-d$ : sõrme- $d$, hamba-d. Ülejäänud käänetes polnud ainsusel ja mitmusel vahet. Grammatilisele arvule osutati näiteks possessiivsufiksite või leksikaalsete vahenditega üks, kõik, mitu, palju jt. Selles ja paariskehaosa sõnade analoogias võibki olla põhjus, miks ka näiteks näpp, sõrm, hammas, varvas, kü̈̈s tähendavad ainsuse obliikvakäänetes mõnikord mitmust (Alvre 1989: 148-158).

\subsection{Semantiline teisenemine}

Alvre järgi on soome-ugri arusaam paarist kui kaheosalisest tervikust ja seda tähistavad ainsusevormid kõige paremini säilinud eesti ja sugulaskeelte kivinenud, eriti just piltliku tähendusega väljendeis:jala peal haigust läbi põdema. Seda ka seal, kus tänapäeva eesti kirjakeel kasutab mitmust, vrd omal jalal seisma, heal kindlal jalal olema ja jalul olema, samas vrd ka omal jalal omil jalul (EKSS). Ainsuse tüvega on tegu näiteks adverbiaalsetes väljendites põlwekil, põlwekile; sisult mitmuslikud on veel anna temale kintsu peale $\sim$ wasta kintsu, warbal 'kikivarvul', warba pääl kõndma (Wied). Alvre rõhutab, et Wiedemanni sõnaraamatus registreeritud XIX sajandi keelekasutuse võrdlus tänapäeva omaga näitab mitmuse tähenduses ainsuse taandarengut (Alvre 1989: 151-155). 


\subsection{Kehaosasõnade mitmuse tähenduses ainsuse- ja mitmusevormid}

Võrdlesime Wiedemanni sõnaraamatus mitmuse tähenduses registreeritud ainsusevorme „Eesti keele mõistelise sõnaraamatu” (EKMS), „Eesti murrete sõnaraamatu” (EMS) ja „Eesti keele seletava sõnaraamatu” (EKSS) materjaliga ning Google'i otsimootori abil ka internetis leiduvaga. Selgub, et mitmuse tähenduses ainsuse taandarengu asemel on põhjust rääkida pigem mõnede, ainsuses või mitmuses kehaosasõnu sisaldavate idioomide käibest taandumisest. Näiteks Wiedemanni sõnaraamatu 67 sõnaühendist, mis sisaldavad sõna jalg ja mille hulgas on nii idiomaatilisi kui ka vabu ühendeid, ei leidu EKMS-is seitset ja EMS-is kuut, EKSS-is ja internetis 26. Tänapäeva keelde ei ole jõudnud näiteks jala-aruline, jalapealne haigus, jala pärast 'jala järgi', jalgu jalutama, ta on lapse jalges alles 'lapseeas, lapseohtu', peast jalgu ehitama. Seevastu fraseologism jalga laskma on esindatud kõigis nimetatud sõnaraamatutes, sisaldades Wiedemannil käändsõna mitmuses (jalgu laskma), EKMS-is nii ainsuses kui mitmuses (jalgu $\sim$ jalga laskma), aga EMS-is, EKSS-is ja internetis ainult ainsuses. Ühel juhul on fraasi käändsõna Wiedemannil mitmuses (kuivi jalu) ja mujal mitmuse kõrval ka ainsuses: kuivi jalu kuiva jalaga. Kui jalg märgib majanduslikku heaolu, siis on see Wiedemannil ainsuses (jalale aitama, jalale tõusma), EKMS-is, EMS-is ja EKSS-is mitmuses: jalule aitama,jalule tõusma. Paistab, et tänapäeval ei kasutata paariskehaosade nimetuste mitmuslikku ainsust mitte harvem kui varem, vaid pigem paralleelselt mitmusega. Seda nii idiomaatilistes kui vabades seostes.

Järgnevalt keskendume kehaosasõnade esinemissagedusele erinevates allkeeltes.

\section{Kehaosasõnade esinemissagedus ja osakaal korpustes}

Allpool toetume põhiliselt kahemõõtmelistele empiirilistele sagedustabelitele, kus on andmed kehaosasõnade ainsuse- ja mitmusevormide esinemise kohta. Kuna arvestame eri korpuste puhul erinevate üksuste eri tüüpi sagedustega, siis ei ole FES-ist, MetafK-st ja etTenTen-ist saadud arvandmed teisendamata kujul üksteisega võrreldavad.

\subsection{Kehaosasõnade tegelik ja oodatav sagedus}

Tabelid 2, 4 ja 6 sisaldavad kehaosasõnade tegelikke sagedusi ja neis on lekseemide tunnuste vahel assotsiatsioon olemas. Samade äärejaotustega homogeensed tabelid 3, 5 ja 7 sisaldavad kehaosasõnade teoreetilisi sagedusi, mida oleks oodata, kui kehaosasõnade ja nende arvu vahel seost poleks. Kahe tunnuse seose puudumisest annabki tunnistust selline tabel, kus lahtrite sagedused (osatähtsustena, $1=100 \%$ ) on leitavad vastavate rea ja veeru sageduste korrutisena (vt Tammaru 2002; Möls 2012).

Valemis $n_{i j}=n_{i .} \times n_{j} / n$ on $n_{i j}$ oodatav sagedus tabeli $i$. reas ja $j$. veerus, $n_{i}$. ja $n_{j}$ on vastavalt sagedustabeli $i$. rea ja $j$. veeru summad ning $n$ on vaatluste arv (Kaart 2013). 
FES-i kehaosasõnade tegelik sagedus

\begin{tabular}{lrrr}
\hline lekseem & sg & pl & kokku \\
\hline käsi & 117 & 55 & 172 \\
jalg & 66 & 110 & 176 \\
suu & 234 & 5 & 239 \\
kokku & 417 & 170 & 587
\end{tabular}

Tabel 4 .

MetafK kehaosasõnade tegelik sagedus

\begin{tabular}{lrrr}
\hline lekseem & sg & pl & kokku \\
\hline käsi & 185 & 109 & 294 \\
jalg & 64 & 159 & 223 \\
suu & 144 & 26 & 170 \\
kokku & 393 & 294 & 687
\end{tabular}

Tabel 6.

etTenTen-i kehaosasõnade tegelik sagedus

\begin{tabular}{lrrr}
\hline lekseem & sg & pl & kokku \\
\hline käsi & 96310 & 39382 & 135692 \\
jalg & 26762 & 35799 & 62561 \\
suu & 32613 & 783 & 33396 \\
kokku & 155685 & 75964 & 231649
\end{tabular}

FES-i kehaosasõnade oodatav sagedus

\begin{tabular}{lrrr}
\hline lekseem & sg & pl & kokku \\
\hline käsi & 122 & 50 & 172 \\
jalg & 125 & 51 & 176 \\
suu & 170 & 69 & 239 \\
kokku & 417 & 170 & 587
\end{tabular}

Tabel 5 .

MetafK kehaosasõnade oodatav sagedus

\begin{tabular}{lrrr}
\hline lekseem & sg & pl & kokku \\
\hline käsi & 168 & 126 & 294 \\
jalg & 128 & 95 & 223 \\
suu & 97 & 73 & 170 \\
kokku & 393 & 294 & 687
\end{tabular}

Tabel 7 .

etTenTen-i kehaosasõnade oodatav sagedus

\begin{tabular}{lrrr}
\hline lekseem & sg & pl & kokku \\
\hline käsi & 91195 & 44497 & 135692 \\
jalg & 42046 & 20515 & 62561 \\
suu & 22445 & 10951 & 33396 \\
kokku & 155685 & 75964 & 231649
\end{tabular}

Seda, kas kehaosasõnade ja nende arvu vaheline assotsiatsioon on statistiliselt oluline, saab uurida hii-ruut-testiga $\left(\chi^{2}\right)$. See universaalne test võrdleb reaalset sagedusjaotust oodatavaga: ${ }^{1}$ kas tegelik jaotus erineb sellest, mis on oodatav antud äärejaotuste korral ja assotsiatsiooni puudumisel. Hii-ruut-testi eeldused on, et ühegi lahtri oodatav sagedus ei ole alla ühe ja et selliseid lahtreid, mille oodatav sagedus on alla viie, ei ole üle $20 \%$ (Tammaru 2002; Gries 2014: 370).

Homogeensusest hälbimist võib iseloomustada suurusega riskide suhe (ingl odds ratio), näiteks lekseemide käsi ja jalg puhul (vt tabelit 2): (117 / 55) / $(66 / 110)=2,127 / 0,6=3,545$. St lekseemi käsi n-ö risk esineda ainsuses on FES-i järgi suurem, kui see on lekseemi jalg puhul (vt ka diagrammid 2-6 allpool). Seose puudumise ehk homogeensuse korral oleks riskide suhe võrdne ühega, st kehaosasõnade ainsuse- ja mitmusevormide jaotus ei sõltuks leksee-

\footnotetext{
${ }^{1}$ Mitte etteantud, näiteks $1: 1$ suhtega.
} 
mist. Mida rohkem riskide suhe ühest ${ }^{2}$ erineb, seda suurem on tunnuste mõju (Tammaru 2002; Gries 2014: 372).

\subsection{Kehaosasõnade suhteline sagedus}

Kehaosasõnade ainsuse- ja mitmusevormide jaotust mõjutavate tunnuste leidmisel võib abi olla kehaosasõnade suhtelise sageduse jälgimisest.

Diagramm 1 näitab kehaosasõnade ainsuse- ja mitmusevormide suhestumist üksteisega. Sõltumata korpusest kaldub kehaosasõnade osakaal ainsusevormide kasuks, erinevused korpuste vahel on väikesed ja jäävad alla 15 protsendipunkti.

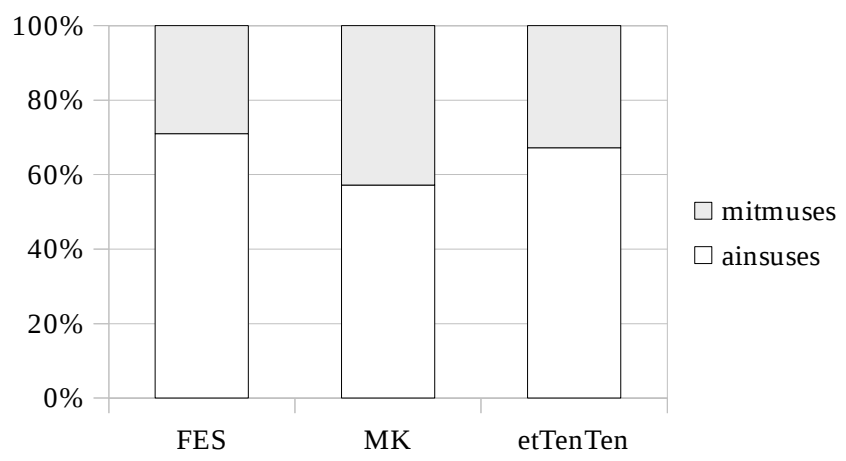

D i a g r a m m 1. Kehaosasõnade ainsuse- ja mitmusevormide osakaal korpustes.

Diagrammid 2 ja 3 iseloomustavad kehaosasõnade suhestumist üksteisega.

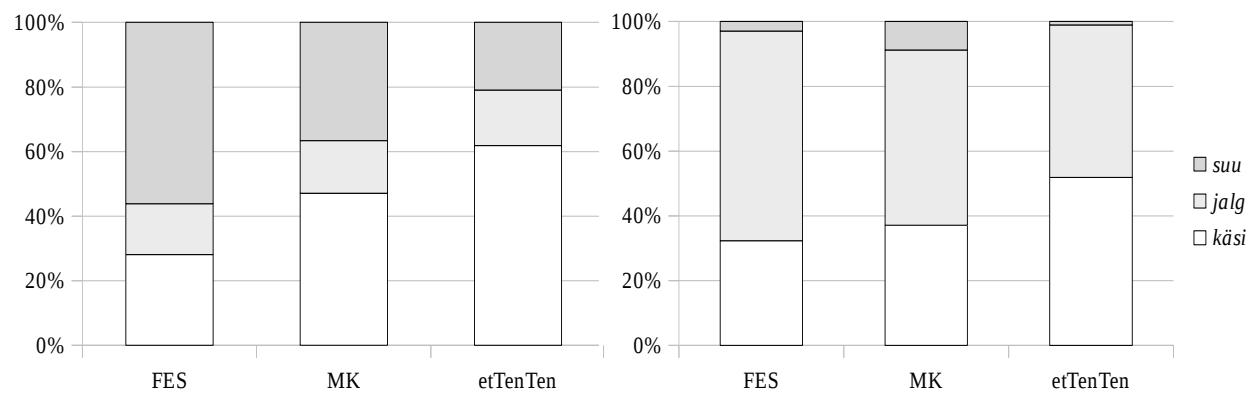

D i a g r a m m 2. Kehaosasõnade ainsusevormide osakaal korpustes.
D i a g r a m m 3. Kehaosasõnade mitmusevormide osakaal korpustes.

\footnotetext{
2 Ja mitte näiteks nullist.
} 
Lekseemi käsi osakaal erineb ainsuses kolme lekseemi ja kolme korpuse võrdluses päris palju: $28 \%$ FES-is vs. $62 \%$ etTenTen-is, mitmuses on vahed väiksemad: $32 \%$ FES-is vs. $52 \%$ etTenTen-is. Lekseemi jalg vormide osakaal on ainsuses 16-17\% ja mitmuses on vahemik sellest mõnevõrra suurem: $47 \%$ etTenTen-is kuni $65 \%$ FES-is. Võimalik, et mitmusevormide sellise osakaalu tingib nimelt arvukategooria tavapärast loogikat järgiv abstraktne 'paari' tähendus. St kui kehaosasõna tähendab 'paar', siis on see pigem mitmuses. Lekseemi suu puhul on olukord teine. Ainsuses on selle vormide osakaal suurim vanemas idiomaatilises materjalis (56 \% FES-is) ja vähim tänapäevases (mitte)idiomaatilises materjalis (21\% etTenTen-is). Suu mitmusevormide osakaal on palju väiksem, 1-9\%. Näeme, et ainsuse ja mitmuse jaotust mõjutab pigem lekseemi tähendus ja mitte allkeelest tulenevad asjaolud.

Diagrammidel 4-6 on korpuste kaupa näha, kuidas suhestuvad üksteisega eri lekseemide ainsuse- ja mitmusevormid.

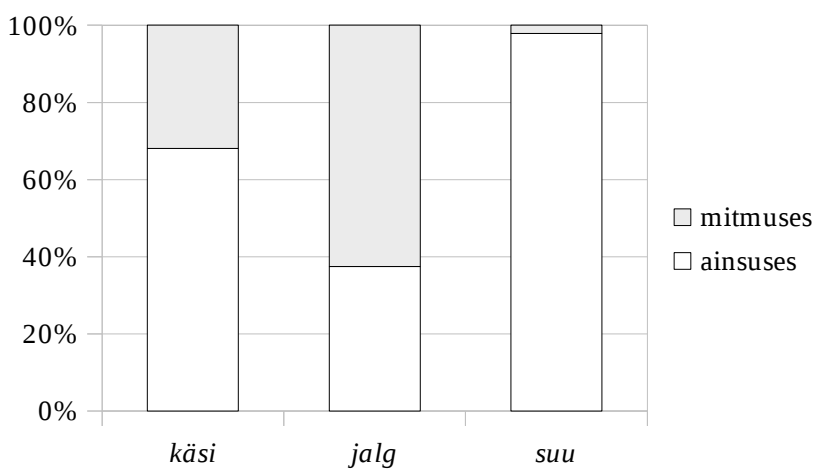

D i a g r a m m 4. Kehaosasõnade ainsuse- ja mitmusevormide osakaal FES-is.

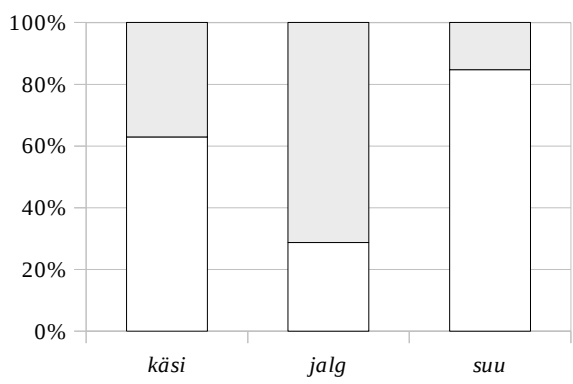

Di a g r a m m 5. Kehaosasõnade ainsuse- ja mitmusevormide osakaal MetafK-s.

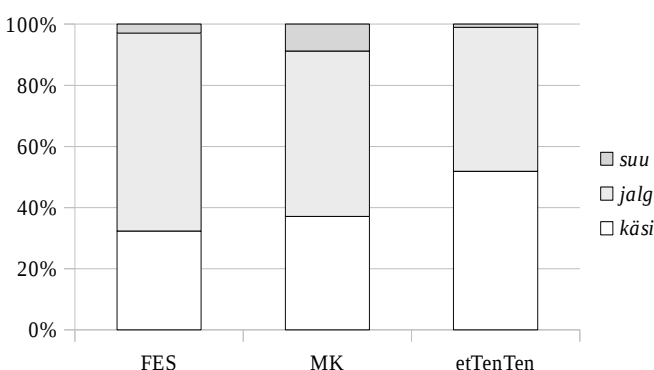

D i a g r a m m 6. Kehaosasõnade ainsuse- ja mitmusevormide osakaal etTenTen-is. 
Lekseemiga käsi on kõigis kolmes korpuses ülekaalus ainsusevormid, mis moodustavad 63-71\% kasutustest ja mis ilmselt tingivad ka diagrammil 1 ilmnenud ainsusevormide üldise suure osakaalu. See võib osalt tulla selle lekseemi kalduvusest adverbialiseeruda, mida võimaldab tähendus 'inimese ülajäse randmest sõrmeotsteni' (EKSS): käes '(ajaliselt) saabunud' (EKSS), näiteks kitsas käes 'vaeselt, kehvalt' (FES). Lekseem jalg esineb pigem mitmuses (71\% MetafK materjalist) ja lekseem suu valdavalt ainsuses (mitmusevorme on taas kõige rohkem, $15 \%$ MetafK materjalis). Vastu ootusi on enim sarnasust vanema idiomaatilise ja tänapäevase idiomaatilise/mitteidiomaatilise materjali osakaaludes.

\section{Seosed kehaosasõnade tunnuste vahel}

Alvre uurimusele toetudes võiksime kehaosasõnade ainsuse- ja mitmusevormide jaotuse mõjutajate selgitamisel keskenduda tabelis 1 esitatud tunnustele, mis tulenevad kolme korpuse andmetest ja struktuurist, ning testida kehaosasõnade arvu seoseid ainult korpustega tervikuna. Kolmandas peatükis kirjeldatud osakaalud selleks otse alust ei anna, pigem paistab kehaosasõnade arv seonduvat neid eristava denotatiivse tähendusega. Kuid kas need seosed kehaosasõnade tunnuste vahel eksisteerivad ka tegelikult või võivad need olla tingitud valimi juhuslikkusest? Kas tegelike sageduste tabelite $(2,4,6)$ erinevus oodatavate sageduste tabelitest (vastavalt 3,5 ja 7 ) on seletatav juhusega või mitte? (Vt Möls 2012; Tammaru 2002; Gries 2014: 370.) Nii FES-is, MetafK-s kui ka etTenTen-is on kehaosasõnade oodatavad sagedused suuremad kui viis. Seega on neile küsimustele vastamiseks õigustatud testida nimetatud seoste olemasolu hüpoteeside statistilise kontrollimisega (vt Kaart 2013).

Tabelis 8 on KONKREETNE TÄHENDUS meie käsitluses multinominaalne tunnus, ${ }^{3}$ mille väärtused erinevad lekseemiti. ABSTRAKTSET TÄHENDUST saab nimetada binominaalseks tunnuseks, mille väärtus tuleb sellest, kas kehaosasõna kannab tähendust 'paar' või mitte (vt Möls 2012). Kuna nii MetafK-s kui ka etTenTen-is on tegu tekstisagedustega, ${ }^{4}$ olgugi et esimesel juhul käib see fraaside või lausekujuliste konstruktsioonide ja teisel juhul ainult lausete kohta, peame võimalikuks käsitleda neid ühe ja sama tunnuse KORPUSED väärtustena.

Tabel 8 .

\section{Kehaosasõnade kvalitatiivsed nominaalsed tunnused}

\begin{tabular}{lccc}
\hline tunnus & käsi & jalg & suu \\
\hline KONKREETNE TÄHENDUS & 'ülajäse' & 'alajäse' & 'huultevaheline ava' \\
ABSTRAKTNE TÄHENDUS & & '+paar' & '-paar' \\
KORPUSED & & MetafK & \\
& & & \\
& & & \\
& & &
\end{tabular}

\footnotetext{
${ }^{3}$ Hii-ruut-test ongi (pea) ainus võimalus seoste olemasolu testimiseks, kui üks uuritav tunnus on nominaalne (Möls 2012).

${ }^{4}$ Seda erinevalt FES-ist (vt eespool).
} 
ARV on kvantitatiivne diskreetne tunnus, mille täisarvulised väärtused on saadud kehaosasõnade ainsuse- ja mitmusevormide loendamise teel (vt Möls 2012) nagu tabelites 2,4 ja 6 .

Hii-ruut-testile vastavad järgmised hüpoteeside paarid.

$\mathrm{H}_{0}$ : kehaosasõna arv ei sõltu kehaosasõna (konkreetsest või abstraktsest) tähendusest;

$\mathrm{H}_{1}$ : kehaosasõna arv sõltub kehaosasõna (konkreetsest või abstraktsest) tähendusest (vt Kaart 2013)

ja

$\mathrm{H}_{0}$ : kehaosasõna arv ei sõltu korpusest, kus see esineb;

$\mathrm{H}_{1}$ : kehaosasõna arv sõltub korpusest, kus see esineb.

Meie hii-ruut-testide tulemused ${ }^{5}$ on tabelis 9 , kus $\chi^{2}$-statistik on teststatistik, mis mõõdab erinevust kontrollitavale nullhüpoteesile vastava sageduse ja tegeliku sageduse vahel. $\chi^{2}$-statistiku väärtuse leidmiseks summeeritakse kõigi tegelike ja oodatavate sageduste ruuterinevus, mis on jagatud oodatavate sagedustega. Kui teooria, s.o nullhüpotees kehtib, siis selle ennustatud oodatavad sagedused peaksid olema ligilähedaselt õiged, tegelike ja oodatavate sageduste vahed väikesed ning $\chi^{2}$-statistiku väärtus samuti väike. Kui teooria ei kehti, siis on tegelike ja oodatavate sageduste vahed (absoluutväärtuselt) pigem suured ning $\chi^{2}$-statistiku väärtus suur.

Selgitamaks välja, kui suur peab olema $\chi^{2}$-statistiku väärtus, et mitte pidada teooriat enam kehtivaks, läheb vaja vabadusastmete arvu. Nullhüpoteesi kehtides on $\chi^{2}$-statistik ligikaudu $\chi^{2}$-jaotusega vabadusastmete arvuga $d f=$ $(k-1)(l-1)$, kus ühel tunnusel on $k$ erinevat väärtust ja teisel $l$ ja need on suuremad kui üks.

Kas kehaosasõnade ainsuse- ja mitmusevormide jaotus sõltub nende konkreetsest tähendusest? Kui see nii pole, siis peaks kehaosasõnade ainsuse- ja mitmusevormide jaotus olema alati ühesugune, ükskõik, milline oleks konkreetne tähendus. See tähendaks mis tahes lekseemide ainsuse- ja mitmusevormide jagunemise ühesugust tõenäosust. Statistiline olulisus $p$ näitab, kui suur on tõenäosus saada üldkogumist vähemalt nii suure erinevuse või tugeva seosega valim, kui üldkogumis seda erinevust või seost tegelikult ei ole. Kui tõenäosus, et nii tugeva seosega valimi saamine ilma seoseta üldkogumist on piisavalt väike ( $p \leq 0,05 ; p$ ei saa olla null), siis loetakse statistika mõttes tõestatuks hüpotees $\mathrm{H}_{1}$ ja seose olemasolu üldkogumis (Kaart 2012; Möls 2012; Tammaru 2002). Näiteks tabeli 9 viimases reas on valimis nähtud seos korpuste ja arvu vahel statistiliselt oluline. Tõenäosus, et see seos on juhuslik, kui üldkogumis midagi sellist ei ole, on äärmiselt väike: 0,000002451\%.

\footnotetext{
${ }^{5}$ Kasutasime online-kalkulaatorit, vt http://home.ubalt.edu/ntsbarsh/Business-stat/otherapplets/Catego.htm (28. XII 2014).
} 
Hii-ruut-testide tulemused

\begin{tabular}{|c|c|c|c|c|c|}
\hline \multicolumn{2}{|c|}{$\begin{array}{l}\text { kehaosasõnade nominaalsed tunnused } \\
\text { ja nende väärtused }\end{array}$} & \multirow{2}{*}{$\begin{array}{l}\text { korpused } \\
\text { FES } \\
\end{array}$} & \multirow{2}{*}{$\begin{array}{r}\chi^{2} \text {-statistik } \\
180,86\end{array}$} & \multirow{2}{*}{$\frac{d f}{2}$} & \multirow{2}{*}{$\begin{array}{r}p \\
5,330 \mathrm{E}-040 \\
\end{array}$} \\
\hline \multirow{3}{*}{$\begin{array}{l}\text { KONKREETNE } \\
\text { TÄHENDUS }\end{array}$} & 'ülajäse' & & & & \\
\hline & 'alajäse' & MetafK & 130,47 & 2 & $4,664 \mathrm{E}-029$ \\
\hline & 'huultevaheline ava' & etTenTen $^{6}$ & 31864,6 & 2 & $6,398 \mathrm{E}-070$ \\
\hline \multirow{3}{*}{$\begin{array}{l}\text { ABSTRAKTNE } \\
\text { TÄHENDUS }\end{array}$} & \multirow{3}{*}{$\begin{array}{l}\text { '+paar' } \\
\text { '-paar' }\end{array}$} & FES & 141,46 & 1 & $1,276 \mathrm{E}-032$ \\
\hline & & MetafK & 69,79 & 1 & $6,597 \mathrm{E}-017$ \\
\hline & & etTenTen & 16414,68 & 1 & 5,852E-005 \\
\hline KORPUSED & $\begin{array}{l}\text { Metafl } \\
\text { etTenT }\end{array}$ & & 31,08 & 1 & $2,451 \mathrm{E}-008$ \\
\hline
\end{tabular}

Kõik testitud seosed kehaosasõnade tunnuste vahel on statistiliselt olulised: $p$ väärtused on palju väiksemad kui 0,05 .

Sellega võime lugeda tõestatuks alternatiivsed hüpoteesid: kehaosasõnade arvu kasutamine sõltub 1) kehaosasõnade tähendusest; 2) korpusematerjali iseloomust. Lekseemide arvueelistused on seotud nende konkreetse ja abstraktse tähendusega: kui vaadeldud korpustes esineb käsi pigem ja suu valdavalt ainsuses, siis lekseemi jalg mitmusevorme on rohkem. Korpuste suhtes paistab kehaosasõnade arvule mõju avaldavat see, kas kehaosasõnu on kasutatud redigeeritud idiomaatilises fraaside ja lausete koosseisus või kuuluvad need idiomaatilistes või otsetähenduses redigeerimata lausetesse, kuigi korpustes on mõlemal juhul eelistatud ainsusevorme.

\section{Kokkuvõtteks}

Lähtudes Paul Alvre ja Kadri Muischneki uurimustest, mis näitavad, et kehaosasõnade arvu võib mõjutada väljenduse idiomaatilisus, oli artikli eesmärk teha kindlaks, 1) mille poolest erineb kehaosasõnade ainsuse ja mitmuse esinemissagedus idiomaatilistes ja mitteidiomaatilistes ühendites vanemas ja tänapäeva keeles; 2) mis võib allkeeliti erinevat ainsuse ja mitmuse jaotust mõjutada ja mis mitte.

Uurimismaterjaliks valiti lekseemide käsi,jalg, suu vormid, mis leiduvad eesti fraseologismide elektroonilises alussõnastikus, tänapäeva eesti keele metafoorsete sõnaühendite korpuses ning eestikeelsete veebilehtede korpuses. Nende korpuste põhjal said kehaosasõnade üksteisega kombineeruvad tunnused (millest olulisimaks peeti ajalist kuuluvust ja tähenduse tüüpi) väga erinevad väärtused.

Kõigepealt arvutati kehaosasõnade ainsuse- ja mitmusevormide reaalsete sageduste põhjal välja nende teoreetilised sagedused ning tehti kindlaks, millised on kehaosasõnade suhtelised sagedused. Kui lekseemi käsi osakaal erineb ainsuses kolme lekseemi ja kolme korpuse võrdluses päris palju, siis mitmuses on vahed väiksemad. Lekseemi jalg vormide osakaal on ainsuses

\footnotetext{
${ }^{6}$ etTenTen-i andmete väga väikeste $p$-väärtuste näitamiseks on $\chi^{2}$-statistiku väärtus jagatud 100-ga.
} 
ühtlaselt madal, mitmuses on vahemik mõnevõrra suurem. Lekseemi suu ainsusevormide osakaal on suurim vanemas idiomaatilises materjalis ja vähim tänapäevases (mitte)idiomaatilises materjalis, mitmusevormide osakaal on palju väiksem. Osakaalud näitavad, et ainsuse ja mitmuse jaotust võib mõjutada pigem kehaosa tähistava lekseemi denotatiivne tähendus ja mitte allkeelest tulenevad asjaolud. Seejärel uuriti hii-ruut-testidega, kas ilmnenud seosed kehaosasõnade tunnuste ning arvu vahel eksisteerivad ka tegelikult, st iseloomustavad kogu valimit, või võivad need tuleneda valimi juhuslikkusest. Kui seoseid ei eksisteeriks, peaks mis tahes lekseemide ainsuse- ja mitmusevormide jagunemise tõenäosus olema ühesugune. Selgus, et valimis nähtud seos kehaosasõnade konkreetse ja abstraktse tähenduse või uuringus kasutatud korpuste ja kehaosasõnade arvu vahel on statistiliselt oluline: tõenäosus, et seosed on juhuslikud ja üldkogumis midagi sellist ei ole, on äärmiselt väike. Niisiis saame öelda, et kehaosasõnade arvu kasutamine sõltub kehaosasõnade tähendusest ja korpusematerjali iseloomust.

\section{Võrgumaterjalid}

Eesti Keele Instituudi tekstikorpus. http://portaal.eki.ee/corpus

EKSS = Eesti keele seletav sõnaraamat 1-6. 2., täiendatud ja parandatud trükk. Toim Margit Langemets, Mai Tiits, Tiia Valdre, Leidi Veskis, Ülle Viks, Piret Voll. Tallinn: Eesti Keele Sihtasutus, 2009. http://www.eki.ee/dict/ekss/

etTenTen = Eestikeelsete veebilehtede korpus. http://www2.keeleveeb.ee/dict/ corpus/ettenten/

FES = Eesti fraseologismide elektrooniline alussõnastik. Koost Asta Õim, Katre Õim. Tartu: Eesti Kirjandusmuuseum, 2011. http://www.folklore.ee/justkui/sonastik Tartu Ülikooli eesti kirjakeele korpus. http://www.cl.ut.ee/korpused/baaskorpus/ Tartu Ülikooli eesti keele koondkorpus. http://www.cl.ut.ee/korpused/segakorpus/

\section{Kirjandus}

Alv r e, Paul 1989. Eesti kirja- ja murdekeele morfoloogiat. (Eesti NSV Teaduste Akadeemia Emakeele Seltsi toimetised 23.) Tallinn: Valgus.

EKMS = Andrus Saareste, Eesti keele mõisteline sõnaraamat I-IV. Stockholm, 1958-1963.

EMS = Eesti murrete sõnaraamat I. Eesti Teaduste Akadeemia Eesti Keele Instituut. Tallinn, 1994.

Gri es, Stefan Th. 2014. Frequency tables, tests, effect sizes, and explorations. - Corpus Methods for Semantics: Quantitative Studies in Polysemy and Synonymy. (Human Cognitive Processing 43.) Toim Dylan Glynn, Justyna Robinson. Amsterdam-Philadelphia: John Benjamins, lk 365-389.

Ka a r t, Tanel 2012. Binaarsete tunnuste analüüsimeetodid. http://ph.emu.ee/ ktanel/bin_tunnuste_analyys/bin_tunnuste_analyys.pdf (28. XII 2014).

K a a r t, Tanel 2013. Andmeanalüüs MS Excelis. http://www.eau.ee/ ktanel/andmeanalyys_excelis/pt82.php (28. XII 2014).

M u i s c h n e k, Kadri 2006. Eesti keele verbikesksed püsiühendid tekstikorpuses. - Emakeele Seltsi aastaraamat, nr 51 (2005). Tallinn, lk 80-106. 
M öls, Märt 2012. Biomeetria bioloogidele. 2012. a sügissemestril toimuva kursuse kodulehekülg. http://www-1.ms.ut.ee/mart/biomeetria2012/ (28. XII 2014).

T a m m a r u, Toomas 2002. Katseandmete analüüs. http://lepo.it.da.ut.ee/ tammarut/stat.htm (28. XII 2014).

Wied = Ferdinand Johann Wiedemann, Eesti-saksa sõnaraamat. Neljas, muutmata trükk teisest, Jakob Hurda redigeeritud väljaandest. Tallinn: Valgus, 1973.

\section{Number in some body-part nouns}

Keywords: Finno-Ugric languages, Estonian, body-part nouns, grammatical number, idiom

The article attempts to find out what factors could possibly affect the grammatical number of the Estonian words käsi 'hand', jalg 'foot' and suu 'mouth'. The material investigated comes from the Electronic Base Dictionary of Estonian Phrases (FES), the Corpus of Modern Estonian Metaphorical Phrases (MetafK) and the Estonian Web Corpus (etTenTen). The article aims to determine (1) the possible differences in the frequency of occurrence of singular and plural forms of the body-part words in idiomatic and non-idiomatic phrases in modern and older language; (2) the possible factors behind the deviations from the normal syntactic and distributional logic of the use of the singular or plural of those words in different sublanguages. In order to find the factors affecting the grammatical number of the body-part terms in question the actual frequencies of the singular and plural forms were counted and, using those results, theoretical frequencies were computed. The statistical significance of the association between word features was tested by chi-square test. It was found that the grammatical number of the body-part words depends on (1) word semantics and (2) specifics of the corpus material. The number preference of the words studied relates to their concrete and abstract meanings, namely, in the investigated corpora käsi (rather) and suu (mostly) occur in the singular, whereas in jalg plural forms predominate. As to corpus influence there seems to be something to do with whether the body-part words are observed in edited idiomatic phrases or sentences or in unedited sentences (no matter if idiomatic or not), although in both cases singular forms are preferred.

Katre Öim (b. 1970), PhD, Tallinn University, Institute of Estonian Language and Culture, Docent of the Estonian Language, katre.oim@tlu.ee

Asta Õim (b. 1943), PhD, asta.oim@gmail.com 